\title{
Atmospheric Corrosion Behavior of Arc Thermal Spray Zn-Al Coatings Using Accelerated Atmospheric Field Test for Ten-Year
}

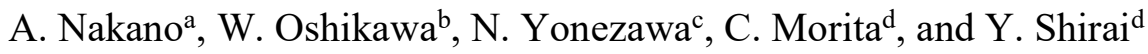 \\ ${ }^{\text {a }}$ Center for Collaborative Research \& Community Cooperation, University of Miyazaki, \\ Miyazaki 889-2192, Japan \\ ${ }^{b}$ Faculty of Engineering, University of the Ryukyus, Okinawa 903-0129, Japan \\ ${ }^{\mathrm{c}}$ DAIHEN Corporation, Osaka 532-8512, Japan \\ d Faculty of Engineering, University of Miyazaki, Miyazaki 889-2192, Japan
}

\begin{abstract}
As a basic study on corrosion life of thermal spray coatings, accelerated field test with artificial seawater for 10-year were carried out for thermal spray Zn-30mass\%Al coatings. By using artificial sea water, atmospheric field test accelerates corrosion due to chloride in comparison with a general atmosphere field test. Thermal sprayed specimens were prepared using an arc thermal spray method with compressed air on carbon steel subjected surface treatment. The formation of the oxide coating and the invasion of $\mathrm{Cl}$ and $\mathrm{S}$ to the inside layer were detected in 10-year of both the atmospheric field and the accelerated atmospheric field exposure tests, but the significant difference in the thickness of the thermal spray coating was not observed. In addition, for the accelerated atmospheric field test with spraying artificial seawater, thermal spray coating part remained satisfactorily, and it showed high corrosion resistance withstanding the 10-year atmospheric field test.
\end{abstract}

\section{Introduction}

Thermal spraying that is one of the surface modification technologies aiming to reduce corrosion of steel structures is an anticorrosion technology to form a film in which metals, ceramics, and plastics with various excellent properties are melted by thermal source such as electricity, and sprayed on the surface of steel substrate. This thermal spraying technology can be applied to considerably wide fields compared to general painting and plating. In addition, it is possible to add advanced performance and functions to this technology, and long-term durability can be expected (1). For film formation process of thermal spray coating to prevent rust, flame spraying and arc spraying are generally used. The excellent properties of arc spraying include the speed of film formation is extremely fast, the adhesion strength and film strength are high, composite-spraying of different metals and pseudo-alloying are possible, and relatively thick films can be obtained. As coating materials, $\mathrm{Zn}, \mathrm{Al}, \mathrm{Mg}$ and their alloys that can be sacrificial anodes have been used $(2-5)$.

As to a method to evaluate the long-term durability of thermal spray coating, an atmospheric exposure field test in nature is well known. Long-term field tests have been conducted in various places in the world (5-21). Long-term atmospheric filed test of the $\mathrm{Zn}, \mathrm{Al}$ and Al-Zn arc spray coatings have been carried out by several studies(19) (22-24). 
Atmospheric exposure tests for various arc sprayed and flame sprayed steels have been conducted in coastal areas for 18 years. As a result, it was found that Al-Zn thermal spray coating has more excellent corrosion resistance than those using elemental metals such as $\mathrm{Zn}$ and $\mathrm{Al}(23)$.

In addition, in indoor accelerated filed tests of salt spray tests (Neutral salt spray test JIS Z2371 or JIS H8502), the formation of blisters and rust was not observed on the surface of the thermal sprayed coating, even when the exposure test time exceeded 10,000 hours, and clear results have not been obtained (25-27). When combined cyclic corrosion tests (Neutral combined cyclic corrosion tests JIS H8502) were applied, results closer to those observed under the actual environment, i.e., the corrosion resistance according to film thickness was higher than the results obtained in salt spray tests, were shown, but there are many issues to be examined regarding its corrosion promotion property (28). As above, the definite life span of the thermal spray coatings is not currently shown, although their good corrosion resistance is shown.

In this study, the corrosion characteristics of thermally-sprayed Zn-30mass\%Al coating is evaluated using an accelerated atmospheric field test. Specifically, atmospheric causticity of thermally-sprayed steel under the accelerated atmospheric field test for 10year is evaluated by comparing with the general atmospheric field test using surface appearance observation and cross-section coating analyses.

\section{Experimental}

\section{Materials}

Properties of the tested materials in this study is shown in Table 1 . The thermallysprayed steel was prepared by thermally spraying a steel sheet $(150 \times 70 \times 2.3 \mathrm{~mm})$, whose surface had been roughly formed by abrasive blasting, by the arc thermally-sprayed with pressurized air. The film thickness of arc thermally-sprayed was used at 3 standards for 90 , 120 and $150 \mu \mathrm{m}$, the composition of the thermal sprayed coating was $\mathrm{Zn}-30 \mathrm{mass} \% \mathrm{Al}$. Sealing treatment on the thermal spray coating was not performed. The spray parameters employed were listed in Table 2. As conditions of the thermal spraying, the compressed air pressure, output potential, output current, wire feed rate, and construction distance were set to be $0.75 \mathrm{MPa}, 20 \mathrm{~V}, 300 \mathrm{~A}, 30 \mathrm{~m} / \mathrm{min}$, and $100-500 \mathrm{~mm}$, respectively. The back side and the edge face of both specimens were painted for protection with anti-corrosion paint, so that the resulting exposed was $59 \times 115 \mathrm{~mm}$. In addition, a line-shaped cut was given to a part of the surface of the thermally-sprayed. The line cut reached to the steel material at the depth deeper than $150 \mu \mathrm{m}$, and the cut width was about $200 \mu \mathrm{m}$.

Table 1 Properties of the tested materials

\begin{tabular}{ccccc}
\hline Materials & Coating method & Mrak on the specimens & Thickness $(\mu \mathrm{m})$ & Exposure period (year) \\
\hline \multirow{3}{*}{ Zn-30wt\%Al } & \multirow{3}{*}{ Arc spraying } & ZNAL90 & 90 & \\
& & ZNAL120 & 120 & 10 \\
& & ZNAL150 & 150 & \\
\hline
\end{tabular}


Table 2 Deposition parameters of the arc spraying process

\begin{tabular}{ccccc}
\hline Air pressure & Spraying Voltage & Spraying Current & Spraying distance & Wire feed rate \\
\hline $0.5-1.0 \mathrm{Mpa}$ & $15-30 \mathrm{~V}$ & $100-400 \mathrm{~A}$ & $10-50 \mathrm{~cm}$ & $10-50 \mathrm{~m} / \mathrm{min}$ \\
\hline
\end{tabular}

Accelerated atmospheric field test

The accelerated atmospheric field test was performed on an exposure footstool, whose exposed area was set up at the horizontal angle of 35 degrees southward in the exposure test field at Okinawa prefecture in Japan. The exposure test was carried out for 10 -year. The artificial seawater used was the one for metal corrosion test that was in conformity with ASTM D1141. Chemical composition of the artificial seawater in this study is shown in Table 3 . The $20 \mathrm{~L}$ of artificial seawater was made by mixing test powder for metal corrosion that is a chloride component shown in Table 3 with distilled water. By manually applying the artificial seawater with brush on the surface of the specimens every 24 hours, and the influence of chloride on the corrosion was promoted compared to the general atmospheric exposure test. The applied amount of the artificial seawater was 2.3 $\times 10^{-3} \mathrm{~L}$, and the influence of chloride on the corrosion was promoted compared to the general atmospheric field test. In addition, the general atmospheric filed test was also carried out about the same time.

Table 3 Chemical composition of the artificial seawater $(\mathrm{g} / \mathrm{L})$

\begin{tabular}{cc|cc}
\hline $\mathrm{NaCl}$ & 24.53 & $\mathrm{NaHCO}_{3}$ & 0.20 \\
$\mathrm{MgCl} \cdot 6 \mathrm{H}_{2} \mathrm{O}$ & 11.11 & $\mathrm{KBr}$ & 0.10 \\
$\mathrm{Na}_{2} \mathrm{SO}_{4}$ (anhydrous) & 4.09 & $\mathrm{SrCl}_{2} \cdot 6 \mathrm{H}_{2} \mathrm{O}$ & 0.04 \\
$\mathrm{CaCl}_{2}$ (anhydrous) & 1.16 & $\mathrm{H}_{3} \mathrm{BO}_{3}$ & 0.03 \\
$\mathrm{KCl}$ & 0.70 & $\mathrm{NaF}$ & 0.003 \\
\hline
\end{tabular}

Surface appearance and film thickness measurement

The appearance of the initial materials and the film surface after 10-year atmospheric field test was visually inspected.

The thicknesses of the coating before and after the atmospheric field test were measured using a digital microscope (VHZ100UR, KEYENCE). Specimens for crosssection analysis were cut into $20 \times 20 \mathrm{~mm}$ pieces, vertically buried in epoxy resin. The thickness was measured at 20 locations in total with $1 \mathrm{~mm}$ equal intervals, and the average value of those measurement was assumed to be mean film thickness.

\section{Elemental map at cross-section of a specimen covered with arc thermal spray coating}

To analyze the elemental mapping of the arc spray coating before and after the atmospheric field test, cross-section was examined with scanning electron microscope (SEM) observation, and element distribution was analyzed with an electron probe microanalyzer (EPMA, JOEL JAX-8230). Acceleration voltage was $15 \mathrm{kV}$, and magnification was $300 \%$. The distribution of $\mathrm{Zn}(\mathrm{L} \alpha), \mathrm{Al}(\mathrm{K} \alpha), \mathrm{O}(\mathrm{K} \alpha), \mathrm{Cl}(\mathrm{K} \alpha)$, and $\mathrm{S}(\mathrm{K} \alpha)$ was examined. 


\section{Results and Discussion}

Corrosion behavior of specimens exposed using accelerated atmospheric field test

Figure 1 shows the surface appearance of thermal spray coating $\mathrm{ZnAl}$ exposed in the accelerated atmospheric field tests for 10-year. For the surface morphology of the initial material, metallic luster was not observed. The film surface was considerably rough and the color of the surface was close to grayish white. For all film thicknesses, white granular corrosion products were generated on the surface of the thermal spray coating throughout the specimens after the 10-year atmospheric exposure test. In the case of the coating with $90 \mu \mathrm{m}$ thickness, the part of the line cut became white, and it could be visually confirmed. For the films with $120 \mu \mathrm{m}$ thickness, the line-cut parts became difficult to be visually confirmed because they were covered with white granular corrosion products. When the film became as thick as $150 \mu \mathrm{m}$, the line-cut parts were completely covered with white granular corrosion products that had been produced after the 10-year atmospheric field test and the line-cut parts could not be visually confirmed.

After the 10-year accelerated atmospheric field test, the surface of thermal spray coating was totally covered with white granular corrosion products at all film thicknesses, which was similar to the atmospheric exposure test, and fine corrosion products increased in addition to the granular corrosion products. As a result, the surface of the thermal spray coating became further whitish compared to that after the atmospheric filed test. For the film with $90 \mu \mathrm{m}$ thickness, red rust was formed in the center of the specimen and the effect of artificial seawater spraying was observed. For the thermal spray coatings with $120 \mu \mathrm{m}$ and $150 \mu \mathrm{m}$ thickness, the line-cut parts were covered with corrosion products. In particular, for the films with $150 \mu \mathrm{m}$ thickness, the amount of fine white corrosion products became so large that the line-cut parts could not be visually confirmed.

These corrosion products were already confirmed by X-ray diffraction (XRD) using specimens after 4-year atmospheric field test (29). After the atmospheric field test, diffraction peaks of $\mathrm{Zn}, \mathrm{Al}$, and $\mathrm{Zn}_{6} \mathrm{Al}_{2}(\mathrm{OH})_{16} \mathrm{CO}_{3} \cdot 4 \mathrm{H}_{2} \mathrm{O}$ (basic $\mathrm{ZnAl}$ carbonate) were observed in both the atmospheric field and the accelerated atmospheric field tests ${ }^{5}$.

As stated above, for thin coating films after 10-year atmospheric field test, the corrosion was promoted by spraying artificial seawater and red rust was formed. For thermal spray coating with the thickness of $100 \mu \mathrm{m}$ or more, although white corrosion products rusted on the entire surface, it showed high corrosion resistance without any effect on the steel substrate. 


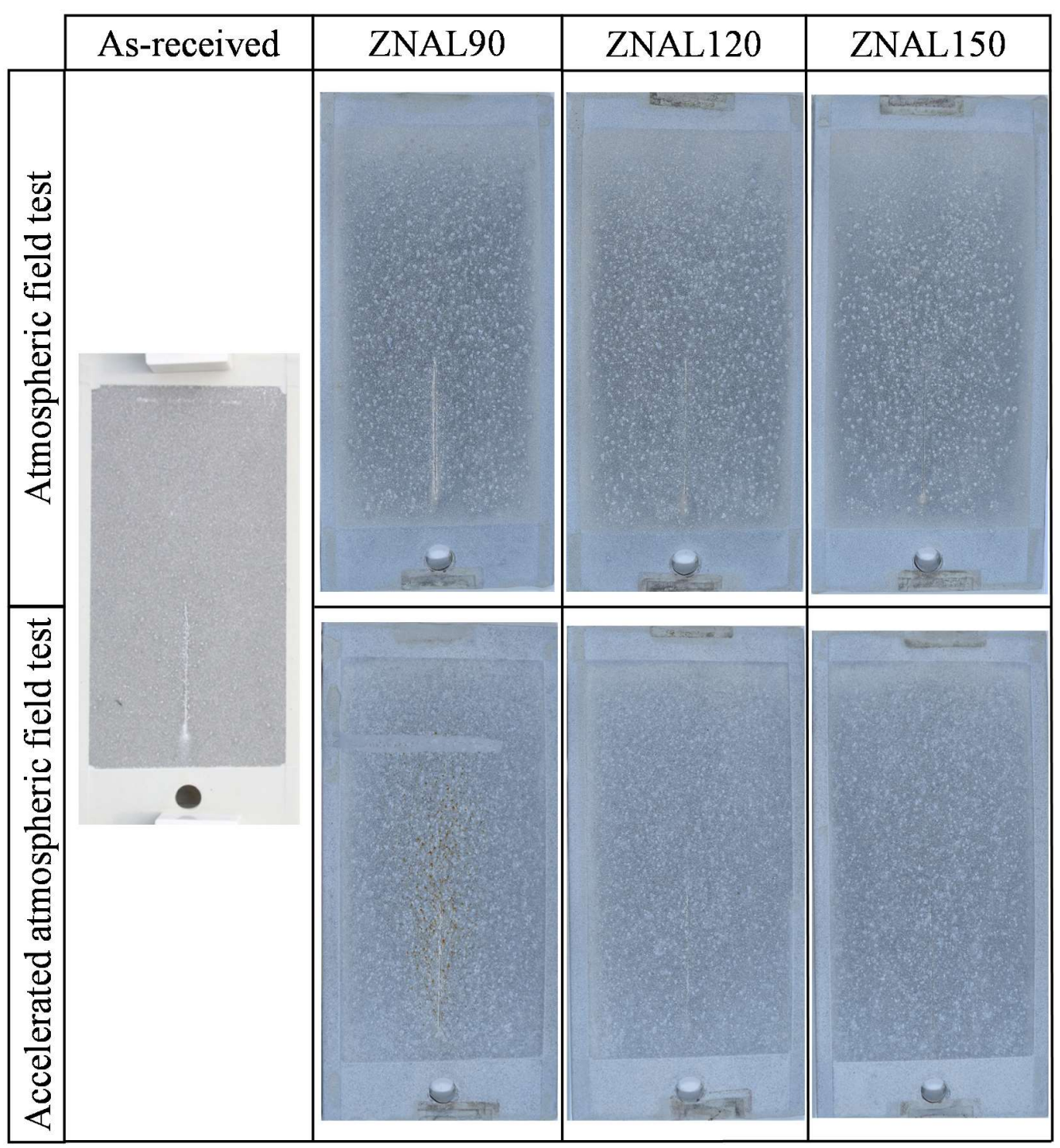

Figure 1 Surface appearance of ZNAL90, ZNAL120 and ZNAL150 thermal spray coatings exposed using accelerated atmospheric field test for 10 years. 


\section{Film thickness measurement of arc spray coating}

The surface of the thermal sprayed coating was formed very coarsely, and the defects such as voids were frequent inside. $\mathrm{Zn}$ and $\mathrm{Al}$ each formed the coating in a layered form as pseudo alloy (28).

Figure 2 shows the film thickness of arc sprayed coating ZNAL90, after 10-year using accelerated atmospheric field tests. The average film thickness of the initial material of the arc sprayed coating was approximately $96 \mu \mathrm{m}$, but the standard deviation of the thickness was large, as the coating surface was very rough. For specimens after 9 -year, the film thickness in both kinds of atmospheric field tests decrease. However, after 10-year atmospheric field test, the average film thickness of the specimens without spraying artificial seawater was about $84 \mu \mathrm{m}$, while that with spraying artificial seawater was about $78 \mu \mathrm{m}$. The results showed that the film thickness after 10-year atmospheric field test slightly increased compared to that after 9-year.

Figure 3 shows the film thickness of arc sprayed coating ZNAL120, after 10-year using accelerated atmospheric field tests. The average film thickness of the initial material of the arc sprayed coating was approximately $116 \mu \mathrm{m}$, but the standard deviation of the thickness was large, as the coating surface was very rough. For specimens after 10-year atmospheric field test, the average film thickness of the specimens without spraying artificial seawater was about $113 \mu \mathrm{m}$, while that with spraying artificial seawater was about $101 \mu \mathrm{m}$, which showed a slight decrease.

Figure 4 shows the film thickness of arc sprayed coating ZNAL150, after 10-year using accelerated atmospheric field tests. The average film thickness of the initial material of the arc sprayed coating was approximately $148 \mu \mathrm{m}$, but the standard deviation of the thickness was large. For specimens without spraying artificial seawater, significant changes were not observed after the 9-year atmospheric field test. For specimens with spraying artificial seawater, the average film thickness slightly increased to about $163 \mu \mathrm{m}$, and the standard deviations were also large. Furthermore, significant difference in film thickness was not observed between samples with and without artificial seawater spraying after the atmospheric field test for 10-year atmospheric field test.

As described above, it was clarified that the thickness of the AlZn150 thermal sprayed steel did not show significant change with or without artificial seawater after the for the 10-year atmospheric field test. In the case of AlZn120, slight decrease in the film thickness was observed for the specimens with artificial seawater after the 10-year atmospheric field test. For AlZn90 where the initial thickness of thermal spray coating was small, the amount of wear increased with the exposing time. However, in tenth year, the amount of wear was larger than that expected from the tendency so far. A possible reason for this result would be that although the film thickness once decreased by internal corrosion caused by defects such as voids inside the thermal spray coating, the thickness again increased due to the deposition of corrosion products. The detailed mechanism of this phenomenon will be left for a subject of future study. To summarize the results, it was suggested that the atmospheric corrosion of $\mathrm{Zn}$-Al thermal sprayed steel depends on the initial film thickness of the thermal spray coating. 


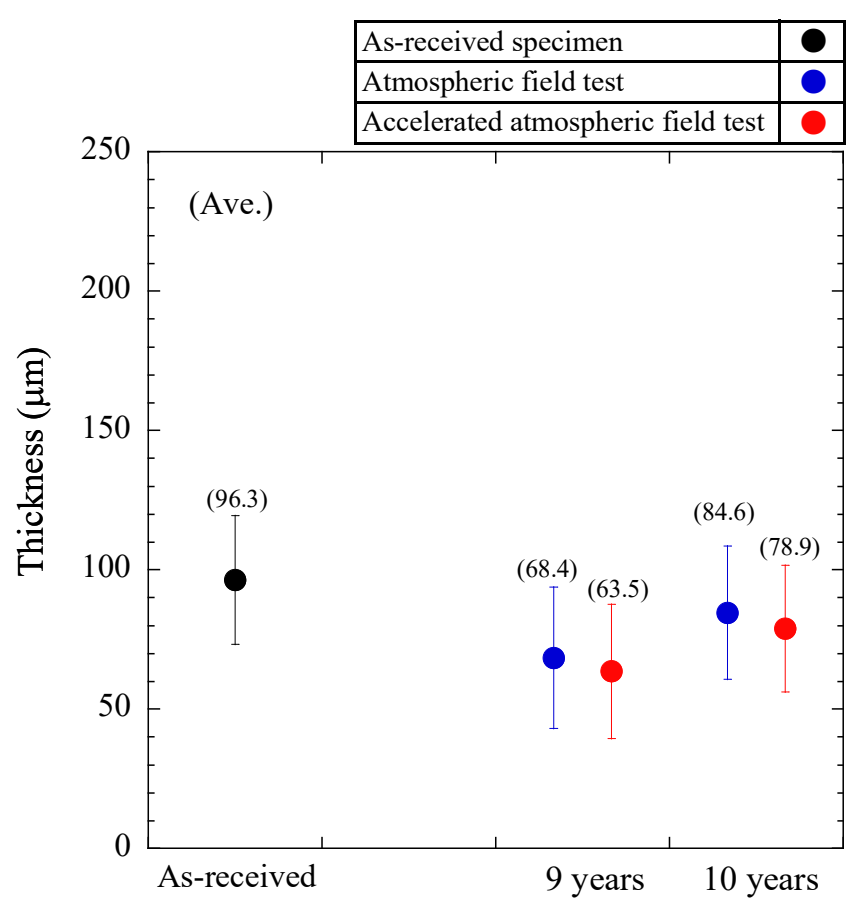

Figure 2 Film thickness of ZNAL90, after 10-year using accelerated atmospheric field test

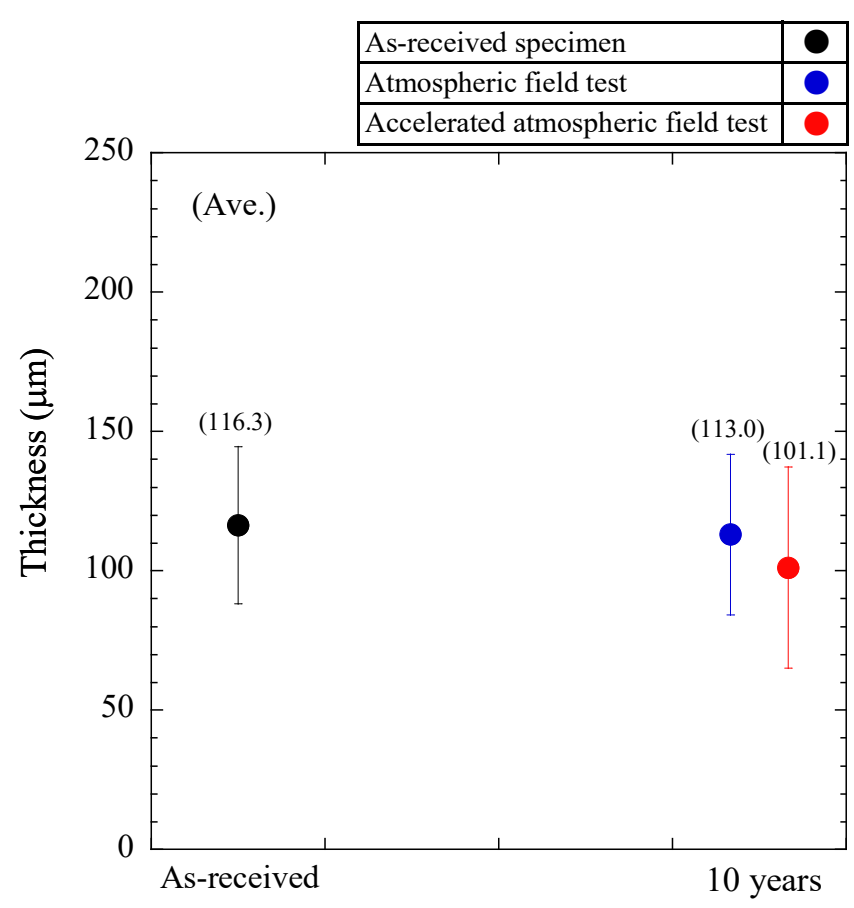

Figure 3 Film thickness of ZNAL120, after 10-year using accelerated atmospheric field test 


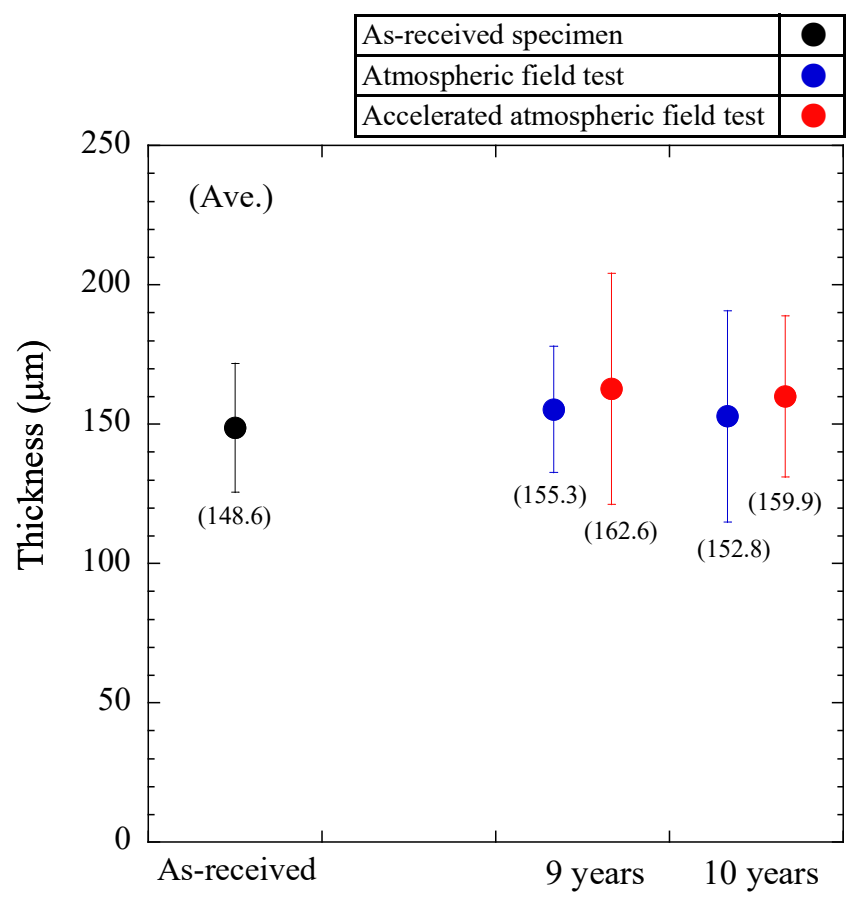

Figure 4 Film thickness of ZNAL150, after 10-year using accelerated atmospheric field test 


\section{SEM images and Elemental mapping images}

Figure 5 shows the SEM images and EPMA elemental mapping for arc sprayed coating ZNAL90 using both atmospheric field and accelerated atmospheric field test for 10 -year. From the SEM images, it was observed that the film thicknesses of thermal spray coating after the 10-year accelerated atmospheric field test slightly decreased compared to those after the atmospheric field test. In both atmospheric field and accelerated atmospheric field tests, layers of oxides of $\mathrm{Zn}$ and $\mathrm{O}$ were formed near the outer layer and inside of the coating. In addition, $\mathrm{S}$ was found inside of the oxide layers of $\mathrm{Zn}$ and $\mathrm{O}$. In the case of the accelerated atmospheric field test, in particular, the oxide layers of $\mathrm{Zn}$ and $\mathrm{O}$ increased compared with atmospheric field test. In addition, when artificial seawater was sprayed in the accelerated atmospheric field test, there were some parts where $\mathrm{Cl}$ intruded into the inside of the thermal spray coating. These results suggested that the $\mathrm{Cl}$ atoms did not originate from airborne salts in the atmospheric field test, but $\mathrm{Cl}$ atoms intruded into the inside the film by spraying artificial seawater. From the SEM images, the film thicknesses of thermal spray coating after the 10-year accelerated atmospheric field test decreased compared to those after the atmospheric field test.

Figure 6 shows the SEM images and EPMA elemental mapping for arc sprayed coating ZNAL120 using both atmospheric field and accelerated atmospheric field test for 10 -year. From the SEM images, the film thicknesses of thermal spray coating after the 10year accelerated atmospheric field test decreases compared to those after the atmospheric field test. In both atmospheric field and accelerated atmospheric field tests, layers of oxides of $\mathrm{Zn}$ and $\mathrm{O}$ were formed near the outer layer and inside of the coating, similar to ZNAL90. In addition, the locations where $\mathrm{Cl}$ penetrated into the inside of the coating by applying artificial seawater were observed, and $\mathrm{O}$ of layers of oxides $\mathrm{Zn}$ and $\mathrm{O}$ increased.

Figure 7 shows the SEM images and EPMA elemental mapping for arc sprayed coating ZNAL150 using both atmospheric field and accelerated atmospheric field test for 10 -year. In the SEM image, large variation in the thickness of the arc sprayed coating in accelerated atmospheric field test for 10-year from that of the atmospheric field test was not observed. In atmospheric field test, layers of oxides of $\mathrm{Zn}$ and $\mathrm{O}$ were formed near the outer layer and inside of the coating. For the accelerated atmospheric field test, oxides composed of $\mathrm{Zn}$ and oxygen on the film surface incraesed compared to those for the atmospheric field test. In addition, Oxygen was slightly detected inside the coating by applying artificial seawater.

As above, in the arc sprayed coating of ZnAl by EPMA analysis, the formation of the oxide coating and the invasion of $\mathrm{Cl}$ and $\mathrm{S}$ to the inside layer were detected in 10-year of both the atmospheric field and the accelerated atmospheric field exposure tests, but the significant difference in the thickness of the thermal spray coating was not observed. In addition, for the accelerated atmospheric field test with spraying artificial seawater, thermal spray coating part remained satisfactorily, and it showed high corrosion resistance withstanding the 10-year atmospheric field test. 


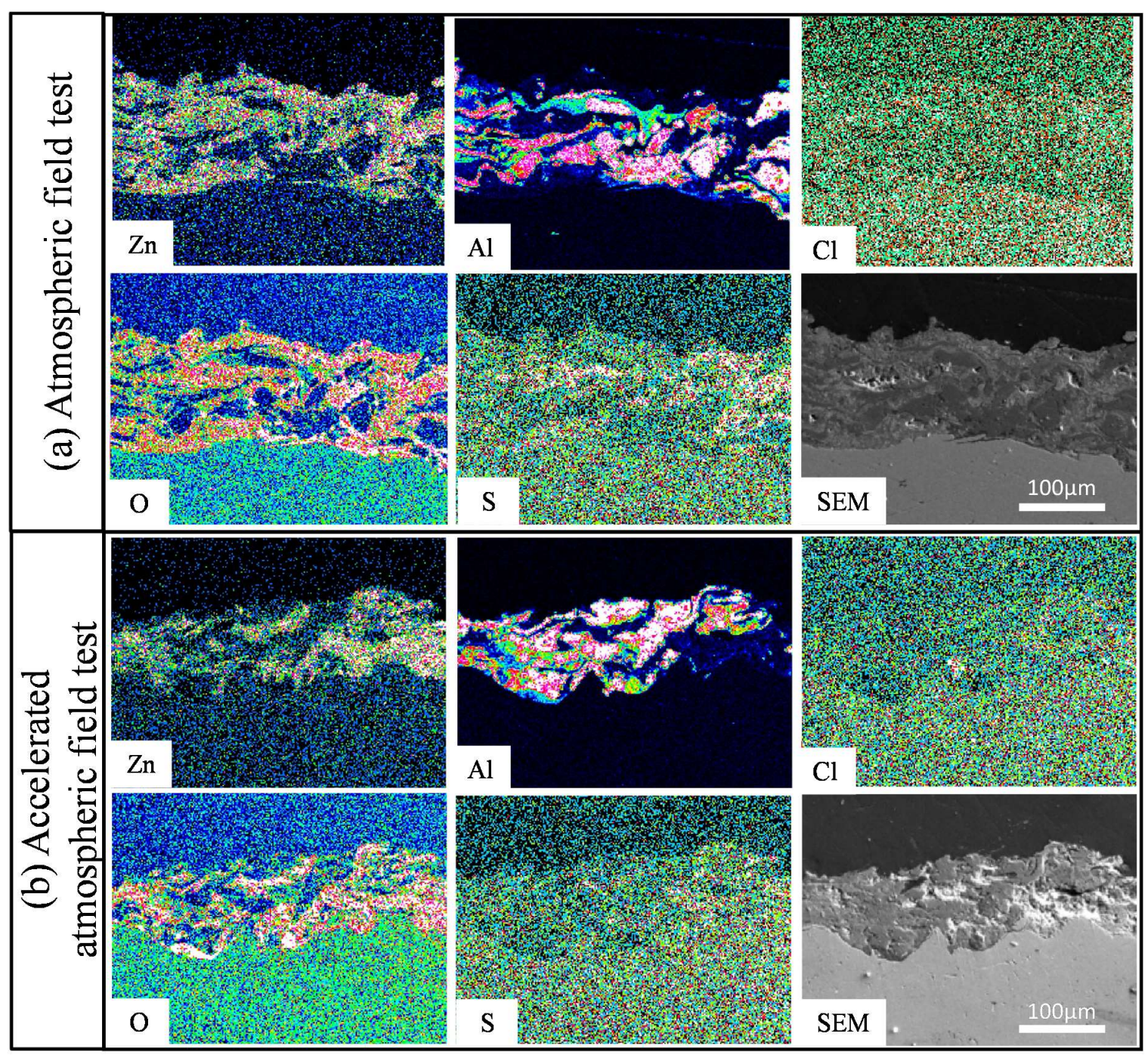

Figure 5 SEM image and EPMA elemental mapping for arc sprayed ZNAL90 exposed for 10 year, (a) atmospheric field test, (b) accelerated atmospheric field test. 


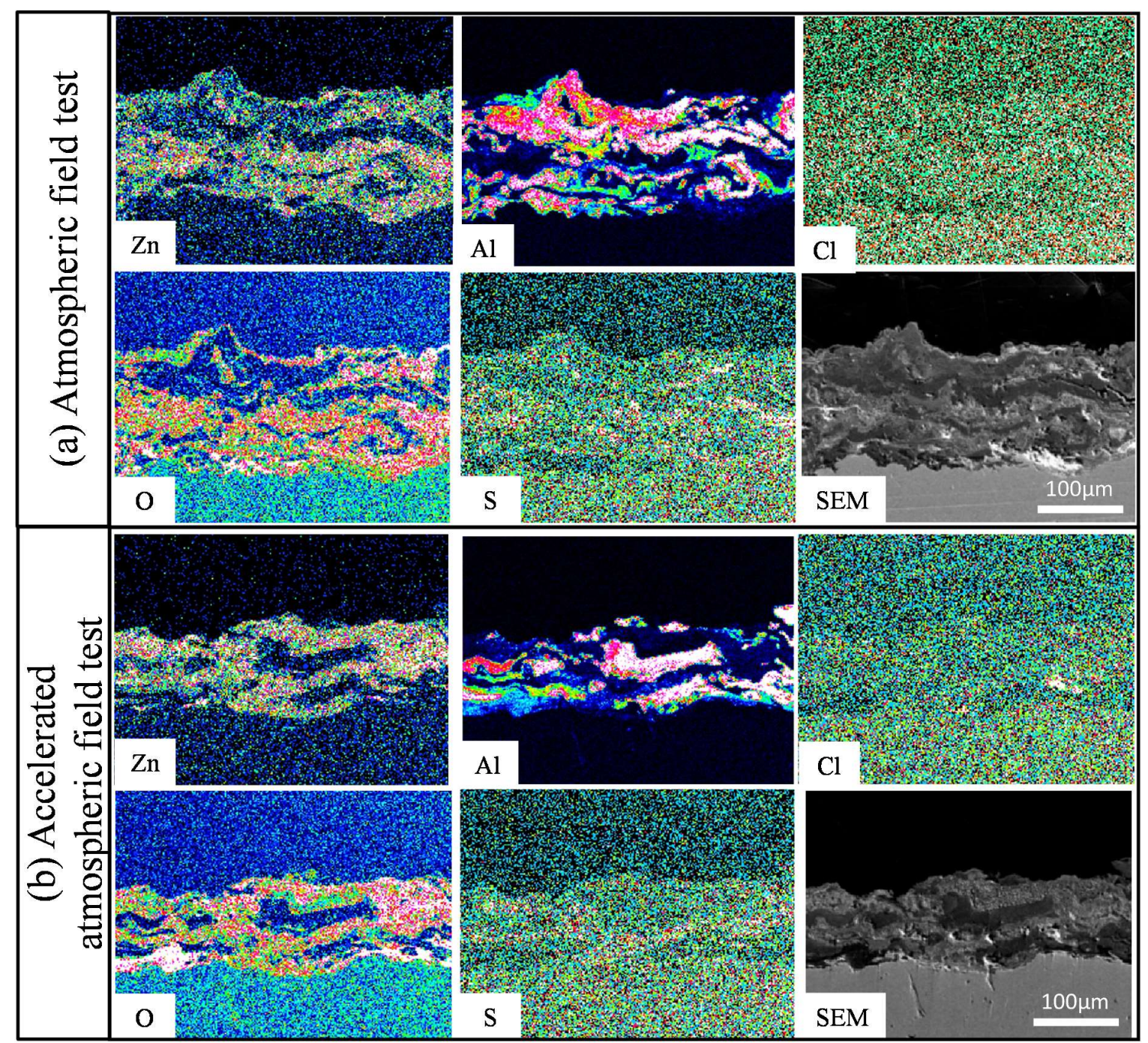

Figure 6 SEM image and EPMA elemental mapping for arc sprayed ZNAL120 exposed for 10 year, (a) atmospheric field test, (b) accelerated atmospheric field test. 


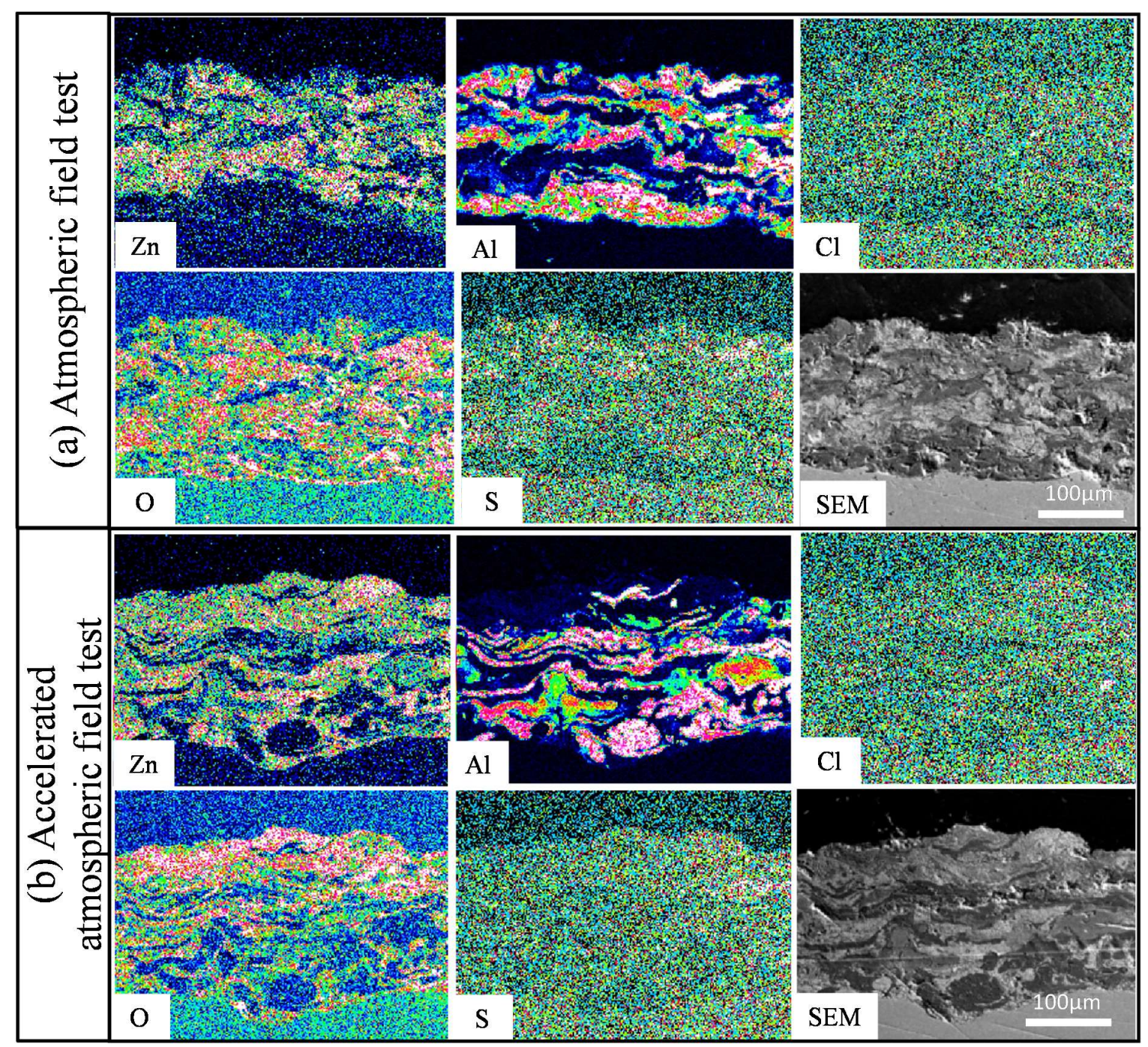

Figure 7 SEM image and EPMA elemental mapping for arc sprayed ZNAL150 exposed for 10 year, (a) atmospheric field test, (b) accelerated atmospheric field test. 


\section{Conclusion}

Ten year atmospheric filed test was conducted for steel with arc thermal spray Al$30 \mathrm{wt} \% \mathrm{Zn}$ coating using the accelerated atmospheric field test with artificial seawater. Atmospheric corrosion was evaluated by surface analysis, measurement of film thickness and EPMA cross-section analysis. The results of the present study are presented below:

1. When the film thickness was small, atmospheric corrosion was promoted by spraying artificial seawater in the 10-year atmospheric field test, and red rust was formed. For the specimens with the film thickness of $100 \mu \mathrm{m}$ or more, although white corrosion products were produced throughout the surface, they showed high corrosion resistance without any effects on the steel substrates.

2. For $\mathrm{Al}-\mathrm{Zn}$ thermal spray coating after the 10 -year atmospheric field test, the significant difference in film thickness was not observed between with and without artificial seawater.

3. EPMA cross-section analysis showed that the $\mathrm{Zn}$ and $\mathrm{Al}$ each formed the coating in a layered form as pseudo alloy. Invasion of $\mathrm{Cl}$ to the inside layer of thermal spray coating was indicated by applying artificial seawater

\section{Acknowledgments}

The authors would like to thank the DAIHEN Corporation for preparing the specimens used in this study.

\section{References}

1. Y. Hirai, Japan Thermal Spray Soc., 75(2), p.142 (2006).

2. Y. Takatani, J. Surf. Finish.Soc.Jpn., 59(8), p.520 (2008).

3. Y. Inui, K. Ueno, Y. Oki, Y. Sugie, S. Sodeoka, Y. Takatani, T. Tomita, YoushaGijyutu-Nyumon, (Japan Thermal Spray Society) p.129 (2012).

4. Y. Takatani, K. Togoshi, R. Shindo, Y. Harada, Yousha, 52(3) p.110 (2015).

5. Y. Takatani, J. High Temperature Soc., 28, p.238 (2002).

6. S. Ueno, Bousei Kanri, 5, p.163 (2004).

7. S. Ueno, Bousei Kanri, 1, p.15 (2008).

8. S. Schuerz, M. Fleischanderl, G. H. Luckeneder, K. Preis, T. Haunschmied, G. Mori, A.C. Kneissl, Corrosion Science, 51, p.2355 (2009)

9. K. Tani, J. High Temperature Soc., 36 p.264 (2010).

10. T. Kobayashi, T. Maruyama, M. Kano, Mater. Trans., 44(12), p.2717 (2003).

11. T. Kobayashi, T. Maruyama, M. Kano, Mater. Trans., 47(7), p.1853 (2006).

12. K. Murakami, Yousha, 46 (2), p.43 (2009).

13. H. Nuriya, T. Suzuki, K. Ishikawa, Y. Kitamura, Zairyo-to-Kankyo, 51(9), p.404 (2002).

14. H. Nuriya, M. Shima, K. Ishikawa, T. Suzuki, Y. Kitamura, Zairyo-to-Kankyo, 58(9), p.64 (2009).

15. H. Nagasaka, S. Uchida, M. Seki, Yousha, 10(2), p.1 (1973). 
16. H. Nagasaka, S. Uchida, M. Seki, Yousha, 12(1), p.233 (1975).

17. S. Kuroda, J. Kawakita, M. Takemoto, Corrosion, 67(7), p.635 (2006)

18. T. P. Hoar, O. Radovici, Proc.6th Int. Conf. Electrodeposition and Metal Finishing, 42, p.211 (1964).

19. R. M. Kain, E.A. Baker, ASTM STP 947, p.211 (1987).

20. H. Katayama, S. Kuroda, Corrosion Science, 76, p.35 (2013).

21. H. Katayama, S. Kuroda, Bousei Kanri, 4, p.27 (2010).

22. Z. Zeng, N. Sakoda, T. Tajiri, J. Therm. Spray Technol., 15, pp. 431 (2006).

23. S. Kuroda, J. Kawakita, M. Takemoto, Corrosion, 62, p. 635 (2006).

24. Tai-Cheng Chen, Chau-Chang, Surf. Coat. Technol. 303, p.78 (2016).

25. B. Tsujino, Yousha, 32(3), p.157 (1995).

26. K. Sonoya, Tetsu-to-Hagane, 92(9), p.567 (2006).

27. J. Shinozaki, I. Muto, H. Ogawa, J. Japan Inst. Metals, 73(7), p.533 (2009).

28. Y. Koga, Yousha, 41 (3), p.109 (2004).

29. A. Nakano, W. Oshikawa, N. Yonezawa, Zairyo-to-Kankyo, 68(7), p.64 (2019). 